\title{
Tubal ligation in relation to menopausal symptoms and breast cancer risk
}

\author{
H B Nichols*,1, D D Baird ${ }^{1}$, L A DeRoo ${ }^{1}$, G E Kissling ${ }^{2}$ and D P Sandler ${ }^{1}$ \\ ${ }^{1}$ Epidemiology Branch, National Institute of Environmental Health Sciences, PO Box 12233, 111 TW Alexander Drive, MD A3-05, \\ Research Triangle Park, NC 27709, USA and ${ }^{2}$ Biostatistics Branch, National Institute of Environmental Health Sciences, \\ 111 TW Alexander Drive, Research Triangle Park, NC 27709, USA
}

Background: Local inflammation after tubal ligation may affect ovarian function and breast cancer risk.

Methods: We analysed tubal ligation, menopausal characteristics, and breast cancer risk in the Sister Study cohort ( $N=50884$ women).

Results: Tubal ligation was associated with hot flashes (hazard ratio (HR) 1.09; 95\% confidence interval (Cl): 1.06-1.12) but not menopausal age (HR 0.99; 95\% Cl: 0.96-1.02). Tubal ligation did not have an impact on breast cancer overall (HR 0.95; 95\% $\mathrm{Cl}$ : 0.85-1.06), but had a suggested inverse relation with oestrogen receptor $+/$ progesterone receptor + invasive tumours (HR 0.84; 95\% Cl: 0.70-1.01), possibly because of subsequent hysterectomy/bilateral oophorectomy.

Conclusion: Tubal ligation does not influence overall breast cancer risk.

The US Collaborative Review of Sterilization reported reduced menstrual bleeding and pain and increased cycle irregularity after tubal ligation (Peterson et al, 2000). These findings provided evidence against a 'post-tubal ligation syndrome' that included dysmenorrhoea and menorrhagia, but could not address long-term outcomes, such as altered menopausal age (Pokoradi et al, 2011), symptoms (Whiteman et al, 2004; Wyshak, 2004; Nelson et al, 2005), or breast cancer risk.

A recent meta-analysis reported no association between tubal ligation and breast cancer $(\mathrm{RR}=0.97)$; however, substantial heterogeneity between studies $\left(I^{2}=82.2 \%, \quad P<0.001\right)$ was observed. Effect estimates among eight studies ranged from $\mathrm{RR}=0.37(0.19,0.68)$ to $1.20(1.00,1.30)$ (Gaudet et al, 2013). This variability may be partly due to incomplete information on subsequent gynaecologic surgeries and tumour subtypes. Women who have a tubal ligation are more likely to undergo hysterectomy (Hillis et al, 1998), which may include bilateral oophorectomy (Lowder et al, 2010), and thereby decrease breast cancer risk. Few studies have evaluated variation by tumours that express oestrogen receptor (ER) or progesterone receptor (PR) and may therefore be more sensitive to hormonal exposures (Eliassen et al, 2006; Press et al, 2011).
We studied tubal ligation in relation to menopausal age, symptoms, and ER/PR-defined breast cancer in the Sister Study.

\section{MATERIALS AND METHODS}

The Sister Study is an ongoing prospective cohort of US women who have a sister who was diagnosed with breast cancer (Godfrey et al, 2013; Xu et al, 2013). During 2003-2009, 50884 women aged 35-74 years completed baseline telephone interviews including reproductive and medical history. All participants are asked to return brief annual health updates and comprehensive biennial questionnaires. Incident breast cancers are initially self-reported and later confirmed by medical record review. Response rates have been $\geqslant 94 \%$ over follow-up. This research was approved by the Institutional Review Boards of the National Institute of Environmental Health Sciences, NIH, and the Copernicus Group. All participants provided informed consent.

Participants reported ever having a tubal ligation and at what age. We excluded 274 women with missing information on tubal ligation or age at tubal ligation, a breast cancer diagnosis preceding

*Correspondence: Dr HB Nichols; E-mail: nicholshb@niehs.nih.gov

Received 25 March 2013; revised 27 June 2013; accepted 4 July 2013; published online 6 August 2013

(c) 2013 Cancer Research UK. All rights reserved 0007-0920/13 


\section{Table 1. PRs and $95 \% \mathrm{Cls}$ for tubal ligation}

\begin{tabular}{|c|c|c|c|c|c|}
\hline & \multicolumn{2}{|c|}{ Tubal ligation } & \multicolumn{2}{|c|}{ No tubal ligation } & \multirow[b]{2}{*}{$\operatorname{PR}(95 \% \mathrm{Cl})^{a}$} \\
\hline & $\mathbf{N}$ & $\%$ & $\mathbf{N}$ & $\%$ & \\
\hline Total & 14802 & 100.0 & 35512 & 100.0 & N/A \\
\hline Age at tubal ligation, mean years (s.d.) & 32.7 & $(5.5)$ & N/A & $\mathrm{N} / \mathrm{A}$ & $\mathrm{N} / \mathrm{A}$ \\
\hline Tubal ligation performed at last birth & 4066 & 27.5 & $\mathrm{~N} / \mathrm{A}$ & N/A & N/A \\
\hline \multicolumn{6}{|l|}{ Education } \\
\hline Less than $\mathrm{HS}$ & 241 & 1.6 & 374 & 1.1 & $1.62(1.47,1.79)$ \\
\hline HS diploma or equivalent & 2614 & 17.7 & 4471 & 12.6 & $1.53(1.47,1.58)$ \\
\hline Some college & 5871 & 39.7 & 11120 & 31.3 & $1.45(1.40,1.49)$ \\
\hline 4-Year college degree or higher & 6076 & 41.0 & 19547 & 55.0 & 1 \\
\hline Latina & 667 & 4.5 & 1670 & 4.7 & $1.04(0.97,1.11)$ \\
\hline Other & 423 & 2.9 & 895 & 2.5 & $1.16(1.07,1.25)$ \\
\hline \multicolumn{6}{|l|}{ Body mass index $\left(\mathrm{kg} \mathrm{m}^{-2}\right)$} \\
\hline$<18.5$ & 123 & 0.8 & 438 & 1.2 & $0.88(0.75,1.03)$ \\
\hline $18.5-24.9$ & 4659 & 31.5 & 14025 & 39.5 & 1 \\
\hline $25.0-29.9$ & 4939 & 33.4 & 11036 & 31.1 & $1.22(1.18,1.27)$ \\
\hline$\geqslant 30.0$ & 5081 & 34.3 & 10013 & 28.2 & $1.34(1.29,1.38)$ \\
\hline \multicolumn{6}{|l|}{ Smoking } \\
\hline Never & 7552 & 51.0 & 19554 & 55.1 & 1 \\
\hline Social & 300 & 2.0 & 843 & 2.4 & $0.95(0.86,1.04)$ \\
\hline Current & 11750 & 79.4 & 29017 & 81.7 & 1 \\
\hline \multicolumn{6}{|l|}{ Parity } \\
\hline 0 & 830 & 5.6 & 8296 & 23.4 & $0.41(0.38,0.45)$ \\
\hline 1 & 1591 & 10.7 & 5653 & 15.9 & 1 \\
\hline $2-3$ & 10323 & 69.7 & 18321 & 51.6 & $1.64(1.56,1.71)$ \\
\hline$\geqslant 4$ & 2058 & 13.9 & 3242 & 9.1 & $1.75(1.65,1.85)$ \\
\hline Age at first birth, mean years (s.d.) & 23.3 & $(4.7)$ & 25.4 & (5.4) & $0.94(0.94,0.95)$ \\
\hline Age at last birth, mean years (s.d.) & 28.5 & $(5.2)$ & 29.7 & (5.4) & $0.97(0.97,0.98)$ \\
\hline \multicolumn{6}{|l|}{ Oral contraceptive use } \\
\hline Never & 1804 & 12.2 & 6239 & 17.6 & 1 \\
\hline Ever & 12998 & 87.8 & 29273 & 82.4 & $1.45(1.39,1.51)$ \\
\hline \multicolumn{6}{|l|}{ Hysterectomy } \\
\hline Never & 9646 & 65.2 & 24897 & 70.1 & 1 \\
\hline Ever & 5156 & 34.8 & 10615 & 29.9 & $1.13(1.10,1.16)$ \\
\hline \multicolumn{6}{|l|}{ Postmenopausal hormone use } \\
\hline Never & 7741 & 52.3 & 21132 & 59.5 & 1 \\
\hline Unopposed oestrogens (E) only & 3185 & 21.5 & 6758 & 19.0 & $1.16(1.12,1.21)$ \\
\hline Combination of $E$ and $E+P$ & 645 & 4.4 & 1354 & 3.8 & $1.16(1.09,1.25)$ \\
\hline
\end{tabular}




\begin{tabular}{|c|c|c|c|c|c|}
\hline & \multicolumn{2}{|c|}{ Tubal ligation } & \multicolumn{2}{|c|}{ No tubal ligation } & \multirow[b]{2}{*}{ PR $(95 \% \mathrm{Cl})^{\mathrm{a}}$} \\
\hline & $N$ & $\%$ & $N$ & $\%$ & \\
\hline \multicolumn{6}{|l|}{ Mammogram screening } \\
\hline Never & 130 & 0.9 & 431 & 1.2 & $0.86(0.74,1.00)$ \\
\hline Ever & 14672 & 99.1 & 35080 & 98.8 & $\mathrm{~N} / \mathrm{A}$ \\
\hline Most recent $<1$ year ago & 11828 & 79.9 & 28662 & 80.7 & 1 \\
\hline Most recent $1-2$ years ago & 2296 & 15.5 & 5109 & 14.4 & $1.07(1.03,1.11)$ \\
\hline Most recent $>2$ years ago & 546 & 3.7 & 1307 & 3.7 & $1.03(0.96,1.11)$ \\
\hline Missing & 2 & 0.0 & 2 & 0.0 & \\
\hline
\end{tabular}

enrolment or with unknown date, or who reported tubal ligation after hysterectomy or menopause. Also excluded were 296 women $(0.6 \%)$ with missing race, education, body mass index, alcohol consumption, oral contraceptive (OC) use, age at menarche, age at first birth, parity, marital status, hysterectomy, or menopausal status. Records from 50314 women were analysed.

Women reported ever having hot flashes and at what age, and whether they ever had 'any other symptoms of menopause such as poor sleeping, night sweats, irritability, or depression' (yes/no) and at what age. Women were considered menopausal after 12 months of amenorrhoea not due to pregnancy or breastfeeding. Age at menopause was defined as a woman's age at last menstrual period.

Women who reported incident breast cancer were asked to provide diagnosis details and authorise the release of medical records. Approximately 10\% declined medical record release or died before providing authorisation. Agreement was high between self-reports and medical records for ER status (95\%) and invasiveness (81\%) (Kim et al, 2011). When medical records were unavailable, self-reported data were used. At the time of this analysis, medical records were available for $77 \%$ of reported breast cancers.

Statistical analyses. Prevalence ratios (PRs) and 95\% confidence intervals (CIs) were calculated from multivariate log-negative binomial regression. To evaluate tubal ligation in relation to menopausal characteristics, we calculated hazard ratios (HRs) and 95\% CIs using Cox proportional hazards models. Women contributed person-time from the age of 30 years to the event of interest (menopause, hot flashes, other menopausal symptoms) or were censored at the age at interview, age at uterine ablation/ embolisation, age at hysterectomy, age at oophorectomy, age at tamoxifen (for chemoprevention) initiation, age at ovarian cancer, or at the age of 60 years, whichever occurred first. Model covariates were selected a priori based on known associations with tubal ligation or menopausal characteristics. Final models adjusted for age at interview, race, education, marital status, body mass index (BMI) during ages 30-39 years, and two time-varying covariates: average number of daily cigarettes from the age of 30-60 years and average number of alcoholic drinks per week during each decade (1930s, 1940s, 1950s). In sensitivity analyses, we adjusted for parity and postmenopausal hormone use and stratified by OC use.

For breast cancer analyses, person-time was accrued from the age at study enrolment. In tumour subtype analyses, competing or undefined subtypes were censored at the date of diagnosis. Final models adjusted for the following covariates a priori as potential confounders: age (as the time scale), education, race, age at menarche, parity, OC use, age at first birth, age at last birth, BMI, and alcohol consumption at enrolment. In sensitivity analyses, we controlled for postmenopausal hormone use and stratified by mammography screening.

\section{RESULTS}

Overall, 14802 women (29.4\%) reported having a tubal ligation (mean age $=32.7$ years; s.d. $=5.5$ ); prevalence was highest among women who reported lower education, African-American race, overweight to obese BMI, current cigarette smoking, ever OC use, younger age at first birth, and having $\geqslant 2$ births. Tubal ligation was also more prevalent among women who reported hysterectomy, postmenopausal hormone use, and mammography screening (Table 1).

Menopause. Women who had a tubal ligation were $9 \%$ more likely to report hot flashes (95\% CI: 1.06-1.12) and 10\% more likely to have other symptoms of menopause (e.g., poor sleeping, night sweats, irritability, depression) (95\% CI: 1.07-1.13) compared with women who did not have a tubal ligation (Table 2). Among those reporting symptoms, $71 \%$ had both hot flashes and other symptoms. Risk of hot flashes did not vary by age at tubal ligation, although other menopausal symptoms appeared more frequent at older ages (HR 1.15: 95\% CI: 1.11-1.20 for tubal ligation $\geqslant 35$ years vs HR 1.07; 95\% CI: 1.03-1.11 for <35; Table 2). In analyses among women who never used OCs or additionally adjusted for parity or postmenopausal hormone use, the results were virtually unchanged (data not shown).

Breast cancer. During 203141 person-years (mean $=4.0$ years), 1646 incident breast cancers were reported (1079 invasive, 422 in situ, 145 undefined). We observed no overall association between breast cancer and tubal ligation (HR 0.95; 95\% CI: 0.85-1.06), or by timing of tubal ligation or subsequent gynaecologic surgery (Table 3).

Oestrogen receptor/PR status was available for $95 \%$ of invasive breast tumours. The $\mathrm{HR}$ for $\mathrm{ER}+/ \mathrm{PR}+$ invasive disease after tubal ligation was 0.84 (95\% CI: 0.70-1.01). Compared with women who reported no tubal ligation, hysterectomy, or bilateral oophorectomy, those who reported tubal ligation and hysterectomy with bilateral oophorectomy had a $42 \%$ decreased risk of $\mathrm{ER}+/ \mathrm{PR}+$ invasive breast cancer $(\mathrm{HR}=0.58 ; 95 \%$ CI: 0.38-0.89). Associations with $\mathrm{ER}+/ \mathrm{PR}+$ invasive tumours were unchanged by adjustment for postmenopausal hormones (data not shown). Tubal ligation was not associated with $\mathrm{ER}-/ \mathrm{PR}-$ invasive breast cancer. 
Table 2. HRs and 95\% Cls for menopausal symptoms and menopause

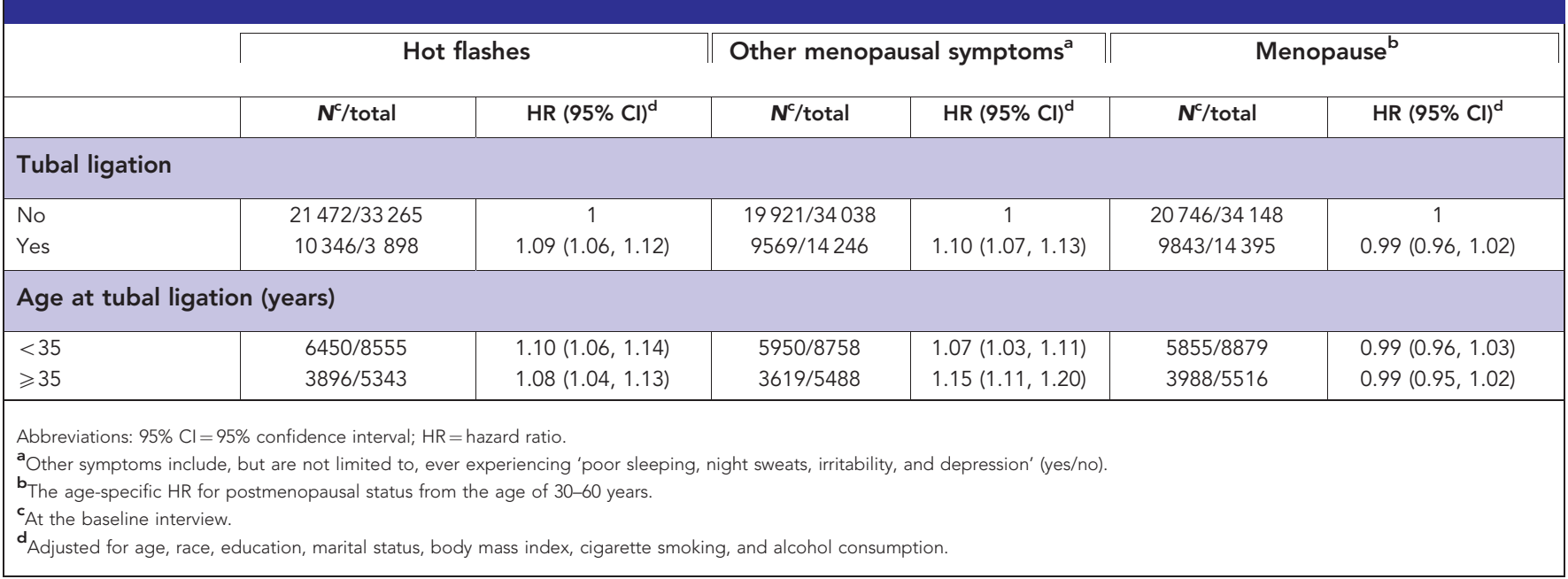

Table 3. HRs and $95 \% \mathrm{Cls}$ for breast cancer

\begin{tabular}{|l||c|c|c|}
\hline Total breast cancer & $\begin{array}{c}\mathrm{ER}+/ \mathrm{PR}+\text { invasive } \\
\text { breast cancer }\end{array}$ & $\begin{array}{c}\mathrm{ER}-/ \mathrm{PR}-\text { invasive } \\
\text { breast cancer }\end{array}$ & In situ breast cancer \\
\hline
\end{tabular}

\begin{tabular}{|c|c|c|c|c|c|c|c|c|c|}
\hline & Person-years & Cases & $\mathrm{HR}(95 \% \mathrm{Cl})^{\mathrm{a}}$ & Cases & $\mathrm{HR}(95 \% \mathrm{Cl})^{\mathrm{a}}$ & Cases & $\mathrm{HR}(95 \% \mathrm{Cl})^{\mathrm{a}}$ & Cases & $\mathrm{HR}(95 \% \mathrm{Cl})^{\mathrm{a}, \mathrm{b}}$ \\
\hline \multicolumn{10}{|c|}{ Overall } \\
\hline \multicolumn{10}{|c|}{ Tubal ligation } \\
\hline No & 144199 & 1192 & 1 & 534 & 1 & 109 & 1 & 293 & 1 \\
\hline Yes & 58942 & 454 & $0.95(0.85,1.06)$ & 173 & $0.84(0.70,1.01)$ & 47 & $0.98(0.68,1.40)$ & 129 & $1.10(0.88,1.37)$ \\
\hline
\end{tabular}

Age at tubal ligation (years)

\begin{tabular}{|r|r|r|r|r|r|r|r|r|r}
\hline$<35$ & 36283 & 270 & $0.98(0.85,1.13)$ & 110 & $0.93(0.75,1.16)$ & 33 & $1.09(0.72,1.66)$ & 66 & $0.95(0.71,1.26)$ \\
$\geqslant 35$ & 22658 & 184 & $0.92(0.78,1.08)$ & 63 & $0.73(0.56,0.95)$ & 14 & $0.81(0.46,1.42)$ & 63 & $1.29(0.98,1.71)$ \\
\hline
\end{tabular}

Years since tubal ligation (years)

\begin{tabular}{|c|c|c|c|c|c|c|c|c|c|}
\hline$<10$ & 4498 & 35 & $1.30(0.92,1.84)$ & 7 & $0.58(0.27,1.23)$ & 3 & $1.37(0.42,4.48)$ & 14 & $2.12(1.20,3.73)$ \\
\hline 10-19 & 14304 & 103 & $1.02(0.83,1.26)$ & 37 & $0.85(0.60,1.20)$ & 12 & $1.20(0.65,2.23)$ & 31 & $1.20(0.81,1.76)$ \\
\hline $20-29$ & 26399 & 186 & $0.86(0.73,1.01)$ & 76 & $0.84(0.65,1.08)$ & 21 & $0.91(0.56,1.48)$ & 56 & $1.03(0.76,1.38)$ \\
\hline$\geqslant 30$ & 13741 & 130 & $0.86(0.80,1.17)$ & 53 & $0.90(0.67,1.22)$ & 11 & $0.85(0.44,1.62)$ & 28 & $0.88(0.59,1.33)$ \\
\hline
\end{tabular}

\section{According to subsequent gynaecologic surgery}

No tubal ligation or

hysterectomy/bilateral

oophorectomy

Tubal ligation alone

Tubal ligation and hysterectomy

alone

Tubal ligation and hysterectomy

with bilateral oophorectomy

\begin{tabular}{|r|r|r|r|r|r|r|r|r|}
\hline 97027 & 766 & 1 & 354 & 1 & 60 & 1 & 193 & 1 \\
36742 & 294 & $1.01(0.88,1.17)$ & 123 & $0.95(0.76,1.18)$ & 32 & $1.38(0.87,2.18)$ & 74 & $1.02(0.77,1.35)$ \\
9080 & 73 & $1.02(0.79,1.31)$ & 23 & $0.74(0.48,1.14)$ & 6 & $0.95(0.40,2.28)$ & 24 & $1.36(0.87,2.12)$ \\
11034 & 76 & $0.83(0.65,1.06)$ & 24 & $0.58(0.38,0.89)$ & 8 & $1.01(0.47,2.20)$ & 26 & $1.17(0.76,1.81)$ \\
& & & & & & & & \\
\end{tabular}

Abbreviations: $95 \% \mathrm{Cl}=95 \%$ confidence interval; $\mathrm{ER}=$ oestrogen receptor; $\mathrm{HR}=$ hazard ratio; $\mathrm{PR}=$ progesterone receptor.

${ }^{a_{H R s} \text { and } 95 \% ~ C l s ~ a r e ~ c a l c u l a t e d ~ f r o m ~ m u l t i v a r i a t e ~ C o x ~ p r o p o r t i o n a l ~ h a z a r d s ~ r e g r e s s i o n ~ m o d e l s ~ a n d ~ a d j u s t e d ~ f o r ~ a g e, ~ a g e ~ a t ~ m e n a r c h e, ~ e d u c a t i o n, ~ r a c e, ~ b o d y ~ m a s s ~ i n d e x, ~ a l c o h o l ~ c o n s u m p t i o n, ~}$ parity, age at first birth, age at last birth, and oral contraceptive use.

${ }^{\mathbf{b}}$ Additionally adjusted for mammography screening.

We observed an increased risk of in situ breast cancer associated with tubal ligation within the past 10 years (HR 2.12; 95\% CI: 1.20-3.73). Among women who reported having a screening mammogram within 12 months of enrolment, this association was no longer statistically significant (HR 1.87; 95\% CI: 0.96-3.62; Supplementary Table).

\section{DISCUSSION}

Women who had a tubal ligation were $\sim 10 \%$ more likely to report menopausal symptoms. Tubal ligation did not alter menopausal age or overall breast cancer risk. We observed a decreased risk of 
$\mathrm{ER}+/ \mathrm{PR}+$ invasive breast cancer associated with tubal ligation among women who also had a hysterectomy with bilateral oophorectomy.

In controlled studies, the majority report a higher prevalence of hot flashes among women with prior tubal ligation (Visvanathan and Wyshak, 2000; Whiteman et al, 2004; Wyshak, 2004). A study of 3650 postmenopausal women in the United Kingdom reported a $38 \%$ increase (95\% CI: $1.02-1.87$ ) in the odds of menopause before the age of 49 years among women who reported tubal ligation (Pokoradi et al, 2011); we did not observe an association between tubal ligation and menopausal age.

Our analysis is one of few to evaluate breast cancer risk according to ER/PR status (Eliassen et al, 2006; Press et al, 2011) or in situ disease. Previous studies were often unable to account for subsequent hysterectomy, which probably contributes to heterogeneity between reports (Gaudet et al, 2013). In our data, decreased breast cancer risk after tubal ligation appeared largely limited to women who also underwent bilateral oophorectomy and to hormonally responsive disease.

Strengths include our large sample and detailed reproductive and lifestyle information. We reconstructed life events from the age of 30 years to interview and used time-varying exposures. Limitations include potential misclassification based on selfreported information. However, in previous studies, hysterectomy and oophorectomy status have been reliably reported (Colditz et al, 1987; Phipps and Buist, 2009; Nichols et al, 2011). All exposure information was reported before diagnosis and was therefore unlikely to bias our results. Subgroup analyses of incident breast cancers were constrained by small numbers, and diagnoses not reported by participants would not have been captured. Our results were robust to covariate selection; however, we cannot exclude the possibility of residual confounding.

In our study, women who had a tubal ligation were more likely to report menopausal symptoms; however, tubal ligation alone did not influence menopausal age or breast cancer risk.

\section{ACKNOWLEDGEMENTS}

This research was supported in part by the Intramural Research Program of the NIH, National Institute of Environmental Health Sciences. Preliminary data were presented at the 36th annual meeting of the American Society of Preventive Oncology, 3-6 March 2012, Washington, DC, USA. The authors appreciate the helpful comments of Drs Matthew Longnecker and Allen Wilcox.

\section{CONFLICT OF INTEREST}

The authors declare no conflict of interest.

\section{REFERENCES}

Colditz GA, Stampfer MJ, Willett WC, Stason WB, Rosner B, Hennekens CH, Speizer FE (1987) Reproducibility and validity of self-reported menopausal status in a prospective cohort study. Am J Epidemiol 126(2): 319-325.

Eliassen AH, Colditz GA, Rosner B, Hankinson SE (2006) Tubal sterilization in relation to breast cancer risk. Int J Cancer 118(8): 2026-2030.

Gaudet MM, Patel AV, Sun J, Teras LR, Gapstur SM (2013) Tubal sterilization and breast cancer incidence: results from the cancer prevention study II nutrition cohort and meta-analysis. Am J Epidemiol 177(6): 492-499.

Godfrey AC, Xu Z, Weinberg CR, Getts RC, Wade PA, Deroo LA, Sandler DP, Taylor JA (2013) Serum microRNA expression as an early marker for breast cancer risk in prospectively collected samples from the Sister Study cohort. Breast Cancer Res 15(3): R42.

Hillis SD, Marchbanks PA, Tylor LR, Peterson HB (1998) Higher hysterectomy risk for sterilized than nonsterilized women: findings from the U.S. Collaborative Review of Sterilization. The U.S. Collaborative Review of Sterilization Working Group. Obstet Gynecol 91(2): 241-246.

Kim S, Sandler DP, Carswell G, De Roo LA, Parks CG, Cawthon R, Weinberg CR, Taylor JA (2011) Telomere length in peripheral blood and breast cancer risk in a prospective case-cohort analysis: results from the Sister Study. Cancer Causes Control: CCC 22(7): 1061-1066.

Lowder JL, Oliphant SS, Ghetti C, Burrows LJ, Meyn LA, Balk J (2010) Prophylactic bilateral oophorectomy or removal of remaining ovary at the time of hysterectomy in the United States, 1979-2004. Am J Obstet Gynecol 202(6): 538, e1-e9.

Nelson DB, Sammel MD, Freeman EW, Gracia CR, Liu L, Langan E (2005) Tubal ligation does not affect hormonal changes during the early menopausal transition. Contraception 71(2): 104-110.

Nichols HB, Visvanathan K, Newcomb PA, Hampton JM, Egan KM, Titus-Ernstoff L, Trentham-Dietz A (2011) Bilateral oophorectomy in relation to risk of postmenopausal breast cancer: confounding by nonmalignant indications for surgery? Am J Epidemiol 173(10): $1111-1120$.

Peterson HB, Jeng G, Folger SG, Hillis SA, Marchbanks PA, Wilcox LS (2000) The risk of menstrual abnormalities after tubal sterilization. U.S. Collaborative Review of Sterilization Working Group. N Engl J Med 343(23): 1681-1687.

Phipps AI, Buist DS (2009) Validation of self-reported history of hysterectomy and oophorectomy among women in an integrated group practice setting. Menopause 16(3): 576-581.

Pokoradi AJ, Iversen L, Hannaford PC (2011) Factors associated with age of onset and type of menopause in a cohort of UK women. Am J Obstet Gynecol 205(1): 34 e1-13.

Press DJ, Sullivan-Halley J, Ursin G, Deapen D, McDonald JA, Strom BL, Norman SA, Simon MS, Marchbanks PA, Folger SG, Liff JM, Burkman RT, Malone KE, Weiss LK, Spirtas R, Bernstein L (2011) Breast cancer risk and ovariectomy, hysterectomy, and tubal sterilization in the women's contraceptive and reproductive experiences study. Am J Epidemiol 173(1): 38-47.

Visvanathan N, Wyshak G (2000) Tubal ligation, menstrual changes, and menopausal symptoms. J Women's Health Gender-based Med 9(5): 521-527.

Whiteman MK, Miller KP, Tomic D, Langenberg P, Flaws JA (2004) Tubal sterilization and hot flashes. Fertil Steril 82(2): 502-504.

Wyshak G (2004) Menopausal symptoms and psychological distress in women with and without tubal sterilization. Psychosomatics 45(5): 403-413.

Xu Z, Bolick SC, Deroo LA, Weinberg CR, Sandler DP, Taylor JA (2013) Epigenome-wide association study of breast cancer using prospectively collected sister study samples. J Natl Cancer Inst 105(10): 694-700.

Supplementary Information accompanies this paper on British Journal of Cancer website (http://www.nature.com/bjc) 